\title{
Long Term Existence of Cement Stabilized Rammed Earth Walls
}

\author{
G.W.T.C. Kandamby
}

\begin{abstract}
It is known that researchers have valued the properties of rammed earth walls in terms of natural comfort, durability, affordability and ecofriendliness. Variety of developments has been introduced continually by them for adoption in building construction. As a result, cement stabilized rammed earth (CSRE) and cement stabilized earth bricks (CSEB) are being used today for constructing load bearing walls of houses in many parts of the world. CSRE has been practiced in Sri Lanka from 2004 and a few housing projects have been successfully completed with minimal cost. CSRE walls in randomly selected housing units in a project were investigated after a period of 13 years and found that these walls are in good condition with the protection of surface coating and little maintenance. CSEB wall junctions, soil erosion near the base of walls especially at the external gable walls are identified as defects of CSRE walls. Defects at CSEB wall junctions have been solved in recent research. Good cooling effect in these houses is highly recognized by the users. High level of supervision is required when constructing CSRE to keep its durability, strength, and especially to gain acceptability from the users.
\end{abstract}

Keywords: Cement stabilized rammed earth, Load bearing walls, Maintenance, Defects, Cooling effect

\section{Introduction}

Rammed earth is one of the developing walling materials for wall construction in buildings in almost all parts of the world due to its features of natural comfort, Eco friendliness, low cost and durability. Over one third of the world's population live in homes built with earth, and over $70 \%$ of the earth's landmass is either pure clay or laterite [1]. Because of the shortage of building materials after World War I, use of rammed earth has comeback during 1920s [2] and new developments have been introduced for the application of rammed earth during the last few years to encourage house builders to select this technology as one of the cost effective housing options. Cement stabilized rammed earth (CSRE) was introduced to the building industry and it is presently used for constructing load bearing walls by following structural design according to New Zealand NZS 4297:1998 or any other earth building code [3].

This technology has been applied in Sri Lanka since 2004 under the guidance of Center for Housing Planning and Building (CHPB) which served as the training and research arm of the Ministry of Housing and Common Amenities. With the disaster of tsunami in December 2004, building of houses was rapidly increased especially along the coastal line of Sri Lanka. At this moment, CHPB was ready to provide all required information of CSRE walling technology as it has the experience on building two model houses at Pelawatta, Battaramulla. Required strength parameter of CSRE was available at this instance for designing the load bearing walls of houses using appropriate codes of practice. A housing project consisting of 35 houses were built for tsunami victims using CSRE load bearing walls in a village Madampagama, Hikkaduwa in Southern Province of Sri Lanka by Mallika Home Society by obtaining the technical support from CHPB. Author of this paper was a member of $\mathrm{CHPB}$ team who engaged in project activities such as designing the housing unit, estimating, training technical staff and masons and supervising the sample house at Madampagama, Hikkaduwa. A house unit has a front verandah, living area, two bed rooms and a kitchen. Cost spent for this house was LKR 425,000.00 in 2005 including supply of water and electricity. Excess soil received from levelling the land of this housing project was used for wall construction so that cost for building CSRE walls could be considerably reduced. Housing units were handed over to the occupants by Mallika Home Society in May 2005 and they have been since occupied, now more than 13 years.

Eng. (Mrs.) G.W.T.C. Kandamby, B.Sc.Eng. (Moratuwa), M.Eng. (Moratuwa), M.Phil. (Moratuwa), C.Eng.FIE (SL), Senior Lecturer, Institution of Technology, University of

Moratuwa.

Email:kndamby@yahoo.com

ORCID ID: https://orcid.org/0000-0003-3934-4022 


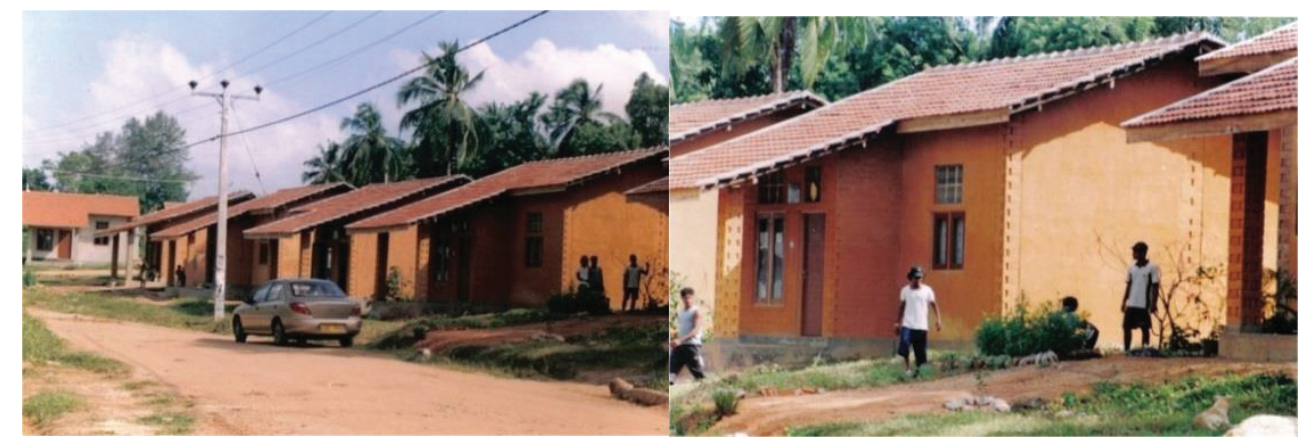

Figure 1 - Completed Housing Project at Madampagama, Hikkaduwa in 2005

\section{Literature Review}

\subsection{CSRE Walling}

Originally rammed earth walls were made with pure earth by ramming manually using timber and rammed earth construction was first recorded by the Babylonians in $5000 \mathrm{BC}$ [4], [5] \& [6]. Major centres of rammed earth construction include North Africa, Australasia, regions of North and South America, China and Europe, including France, Germany and Spain [7]. A great variety of rammed earth techniques has been used in different parts of the world by using local soils. New Zealand research has indicated that monolithic earth walls perform better under earthquake conditions than walls made of separate bricks or blocks [7]. Many rammed earth houses are still standing and it has been further developed by stabilizing earth using cement to increase its strength and durability. Cement was investigated as a good stabilizer for earth building technique due to its good binding property and high strength [8]. Cement stabilized rammed earth is a mixture of soil, Portland cement and water compacted mechanically or manually in a mould to make a dense mass. A detailed study has proven that cement stabilized rammed earth has comparable performance as a walling material [5]. Laterite soil has been recommended for cement stabilized rammed earth construction [8]. The experimental programme on durability properties of earth buildings indicated that cement content above 5\% may be able to almost eliminate durability related problems. It further revealed that laterite soil available in Sri Lanka could give durable and strong walls with at least 5\% cement for stabilization [9]. The basic control factors for satisfactory achievement in cement stabilization are selection of good soil, adequate cement content, proper moisture content and adequate compaction. Selection of soil for CSRE technology is taken for granted and maintained less than $30 \%$ clay content while performing the research activities on load bearing walls. On site soil has been selected through jar test as jar test has proved accurate results in previous experimental works. The composition of $5-20 \%$ gravel, $45-60 \%$ sand, 20 $35 \%$ silt and clay has been recommended for better performance of wall construction. Composition can be checked by performing a jar test [9]. Careful selection of the earthen materials for a CSRE wall is required consistently to maintain the required minimum strength and each soil mix must be analyzed and tested to determine the appropriate amount of cement required to meet the minimum strength specified [10].

Cement stabilized earth compressed bricks (CSEB) have also been introduced as a new alternative walling material and it has been widely spread in the housing sector due to its affordability and suitability to the environment. According to the experimental programmes carried out, it is found that CSEB can provide stronger walls which may be used even as load bearing walls of two storey houses with different types of bond patterns [11]. CSEB has been selected for building junctions of CSRE walls in load bearing walls as vertical guides for casting CSRE walls using steel slip-form $[12,13]$. CSRE walls along with CSEB wall junctions have been applied in several housing projects in Sri Lanka at the initial stages of the development of CSRE technology. Instead of making CSEB wall junctions, CSRE wall junctions have been introduced later to avoid the separation cracks at CSEB wall junctions. This method was successfully applied in a house construction at Akkuressa, Sri Lanka as a cost effective technology for housing [14]. Soil can be found almost everywhere in the country at low cost. Steel or plywood timber sheet can be used for moulds when making walls so that surfaces of the wall can be finished without additional cement plaster. Hence cost can be further reduced. Use of sand can be limited in this technology as sand is not necessary for wall making. This is cost effective technology as it reduces both material cost and labour cost. 
Affordable housing does not mean lack of standards. Structural design and guidelines for building rammed earth walls have been described for one or two storey buildings based on limiting geometry and axial compressive stress [6]. CSRE load bearing walls have been designed according to Masonry code of practice BS 5628: Part 1-2005 [15] and constructed in two storey houses in Sri Lanka using steel-slip form moulds for the purpose of disseminating the technology as an affordable housing method [13]. Same technology has been used for building load bearing walls of two storey houses with timber moulds and CSRE wall junctions by designing the walls structurally using New Zealand code of practiceNZS 4297:1998 [3].

\subsection{Durability of CSRE}

Durability is a parameter which is a concern when selecting any material or method of production. Governing factor of durability is the life span of the structure, the way of treating repairs and maintenance. This is a very critical issue for an earthen structure as it is liable to attack by the environment. Earthen buildings in Spain are usually in a terrible state of decay and owners prefer to demolish them instead of repairing [16]. Many historic examples from around the world are a clear demonstration of the durability of natural earth as a material in a wide variety of building types, techniques, climates and cultures. Key factors in this success are good design and detailing followed by regular maintenance and repair when necessary [7]. With attention to construction details and with a reasonable amount of routine maintenance, simple beachfront construction can last a very long time [17]. History of earth buildings around the world provides good evidence for durability. Even earthen homes in Sri Lanka have lasted more than 100 years and it is understood that sufficient external coats for walls and width of eaves are the main requirements of protecting walls from the effect of water. Due to being constructed using soil, the structures are particularly vulnerable to decay caused by environmental factors such as rain, wind and water flow [4]. Rammed earth possesses a generally high durability but all types of rammed earth walls are porous by nature and need protection from driving rain and long term exposure to moisture [10]. Defects in rammed earth that arise after construction include shrinkage and separation cracking at wall junctions. They may be due to the deficiencies of surface coatings, poor construction methods or structural defects.
Though there are some possible defects in earthen buildings and adverse effects on durability, earth has been identified as the alternative material for building walls of houses. Shrinkage cracks can be limited if drying out of the wall is carefully controlled, the clay content of the soil reduced and movement joints introduced [7]. Despite having a long and acceptable history in architecture, many associate earth use with poverty and under-development [18]. Rammed earth technology has developed through recent research and presently CSRE has been used in most parts of the world as a modern earthen building technology. Rammed earth popularity surged again during the 1970s when resources were once again limited and there was more of an emphasis on how humans impacted the environment. Rammed earth, as one of the oldest building methods, was seen as a good alternative to the usual building materials for its abundance and its low impact on nature [2].

\section{Objectives}

This study was based on a housing project at Madampagama, Hikkaduwa in order to;

i. Examine existing conditions of CSRE walls in single storey houses after 13 years.

ii. Identify possible defects of CSRE walls when using for a 13 years period.

iii. Find the level of maintenance required for CSRE walls.

iv. Assess the user's perceptions on CSRE walls.

\section{Methodology}

Data collection was done in this study under following two procedures.

a) Visit and observe the CSRE walls in houses at Madampagama housing project to cover following information of CSRE walls of randomly selected housing units.

i. Wall cracks.

ii. Erosion of earth walls.

iii. Changes in wall finishes.

iv. Repairs.

v. Modifications.

b) Questionnaire was filled by author to collect following information of CSRE walls through discussions with users of randomly selected houses.

i. Durability.

ii. Living conditions.

iii. Maintenance.

iv. Cooling effect. 
The combination of the above two procedures will help to reveal a broader view of existence of CSRE walls after a 13 years period and to find users' perceptions on CSRE walls for housing.

\section{Data Collection}

Houses were randomly inspected (15 housing units)in August 2018 and discussed with users about their experience on living in earth buildings. Their views were recorded under the following areas.

i. Durability of CSRE walls.

ii. Maintenance.

iii. Repairs.

iv. Cooling effect.

The technical information on performance of CSRE walls during the 13 year period was recorded as follows.

i. Wall cracks.

ii. Separation of walls at CSEB wall junctions.

iii. Application of lime wash.

iv. Separation of wall plaster.

v. Soil erosion.

vi. Modifications.

vii. Evidence of poor quality construction on inspection at the time of data collection.

\section{Analysis of Data}

\subsection{Surface Coating}

It was found that in all inspected housing units occupants had applied either lime wash or emulsion painton the surface of the walls, especially inside the houses. Users said that when they touch walls, earth marks remained in their hands, sometimes on their body or cloth. Donor has taken action at initial stages to plaster walls in a few houses because of the requests from users.
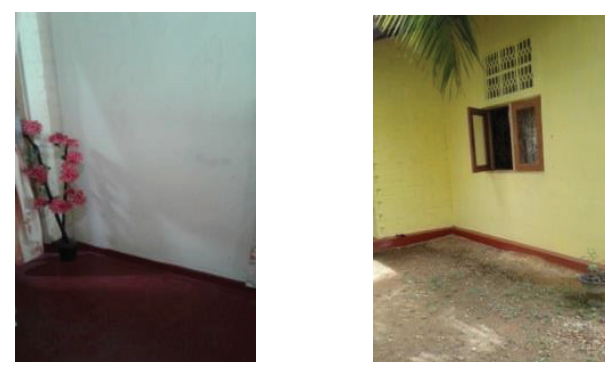

Figure 2 - Surface Coating and Painting

\subsection{Existing Condition of CSRE Walls}

To evaluate the existing condition of CSRE walls, according to the identified defects on
CSRE walls, inspected houses are listed under three conditions as follows.

1. Good condition - No defects during past 13 years period

2. Moderate condition - Only cracks at junction of CSEB corners.

3. Poor condition - Soil erosion, cracks at wall junction of CSEB corners and separation of wall plaster.

Table 1 - Existing Condition of CSRE Walls

\begin{tabular}{|c|c|c|}
\hline Conditions & Housing No. & $\begin{array}{l}\text { No. of } \\
\text { Houses }\end{array}$ \\
\hline Good & $\begin{array}{l}03,22,29,30,31,32, \\
33,34,35,\end{array}$ & $09(60 \%)$ \\
\hline Moderate & $01,02,14,28$ & $04(27 \%)$ \\
\hline Poor & 15,16 & $02(13 \%)$ \\
\hline
\end{tabular}

\subsection{Identified Defects}

Wall deterioration is analyzed for CSRE walls in moderate and poor conditions (6 houses) under the defects identified (see Table 2) in house inspections. Summary of the information collected are presented against the defects identified.

Table 2 - Identified Defects on CSRE Walls

\begin{tabular}{|c|c|c|}
\hline Defects & $\begin{array}{l}\text { Housing } \\
\text { unit No. }\end{array}$ & $\begin{array}{l}\text { No. of } \\
\text { Houses }\end{array}$ \\
\hline $\begin{array}{l}\text { Separation cracks (1 } \\
\text { to } 3 \mathrm{~m} \text { length)at } \\
\text { CSEB wall junctions }\end{array}$ & $16,15,14,28$ & 04 \\
\hline $\begin{array}{l}\text { Separation of wall } \\
\text { plaster }\end{array}$ & 01,02, & 02 \\
\hline $\begin{array}{l}\text { Soil erosion at the } \\
\text { base of the walls }\end{array}$ & $01,02,16,15$ & 04 \\
\hline $\begin{array}{l}\text { Water born soil } \\
\text { erosion }\end{array}$ & 15,16 & 02 \\
\hline
\end{tabular}

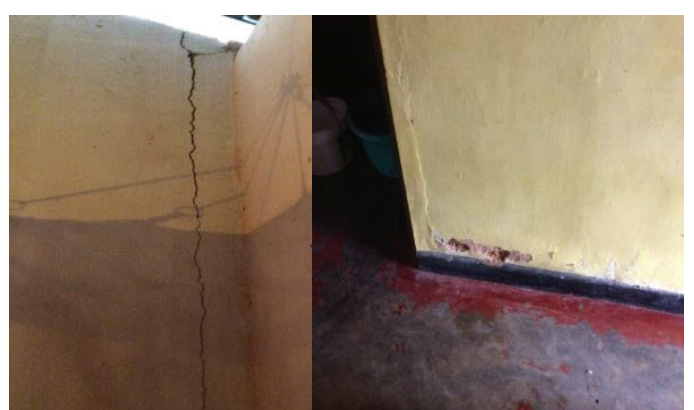

$\begin{array}{ll}\text { (a) Separation crack } & \text { (b) Soil erosion }\end{array}$

Figure 3 - Defects in CSRE Walla

6.4 Users' Comments on CSRE Walls

Data collected from the users were tabulated in Table 3 to evaluate their comments on CSRE walls. 
Table 3 - Occupants' Comments on CSRE Walls

\begin{tabular}{|c|c|c|}
\hline Discussed Areas & $\begin{array}{l}\text { Housing unit } \\
\text { No. }\end{array}$ & $\begin{array}{l}\text { No. of } \\
\text { Houses }\end{array}$ \\
\hline 1. Durability & \multicolumn{2}{|c|}{ Varied ideas } \\
\hline 2. Strength & & \\
\hline a) Satisfied & $29,31,34,35$ & 04 \\
\hline b)Not Satisfied & 15,16 & 02 \\
\hline c) No idea & $\begin{array}{c}01,02,03,14 \\
28,30,33\end{array}$ & 07 \\
\hline 3. Poor quality & $\begin{array}{l}15,16,01,02 \\
14,28,30,33\end{array}$ & 08 \\
\hline 4. Cooling effect & All users & 13 \\
\hline
\end{tabular}

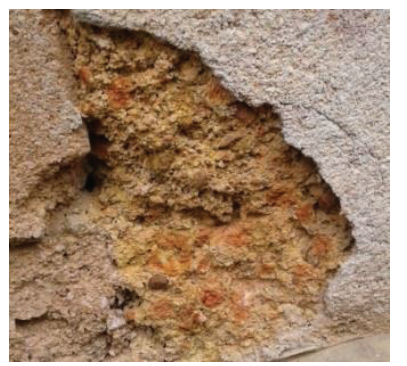

Figure 4 - Soil erosion in House 15 (Base of external wall)

Since No. 15 and 16 houses have wall separation cracks they are not satisfied with CSRE walls. They think that these walls have low durability than other walling materials. They have experience in its deterioration and highly criticized quality of construction. They mentioned that these walls may have high strength but the failure is due to poor method of construction. Users in houses No. 33, 34 and 35 happily said that they received sample houses and there are no defects.
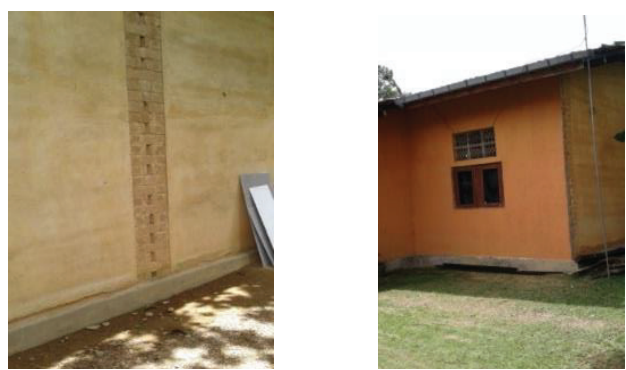

Figure 5 - Sample Houses

CSRE walls are new technology for these users; hence they are not in position to recommend durability or strength of CSRE walls. However 11 families (84\%) are living in these houses without fear. Users have experience in living in cement block work houses and they believe cement blockwork is the best method for wall construction. According to their 13 years of experience all users said that there is a good cooling effect than cement block work.

\subsection{Maintenance}

CSRE wall existence or conditions are analyzed with respect to the method of maintaining these houses by the users during the past 13 year period. Housing units are categorized into four as follows. Cleaning is a constitute part of building maintenance activities [19].

Category A - Well maintained house where no deterioration of CSRE walls were observed.

Category B - Well maintained house where surface coating has been applied on CSRE walls and painted. Wall cracks have been repaired.

Category C - Poorly maintained house where surface coating has been applied on CSRE walls and painted. Wall cracks have not been repaired.

Category D - Modified house

House modified by the users by adding one or more compartments using cement block masonry walls, applying surface coatings, plastering walls, painting, fixing ceilings and laying floor tiles and wall tiles in kitchen and bath areas.

Table 4 - Summary of Maintenance

\begin{tabular}{|c|c|c|}
\hline Category & Housing Unit No. & $\begin{array}{c}\text { No. of } \\
\text { Houses }\end{array}$ \\
\hline A & $03,29,30,33,34,35$ & $06(46 \%)$ \\
B & 14,28 & $02(15 \%)$ \\
C & $16,15,01,02$ & $04(31 \%)$ \\
D & 31 & 01 \\
\hline
\end{tabular}
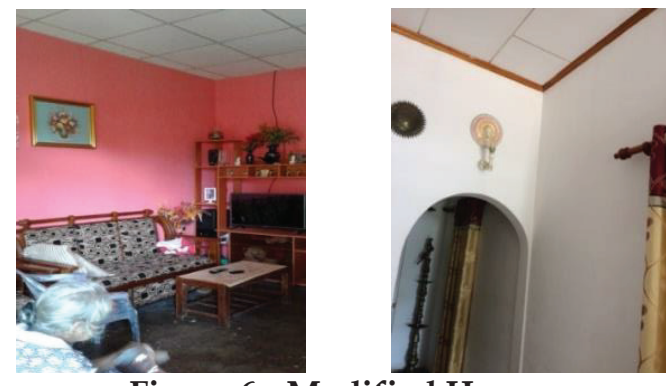

Figure 6 - Modified Houses

It is found that about $61 \%$ of users have taken good attempts to maintain these houses satisfactorily but $31 \%$ of users have poorly maintained due to their economic condition. All elements of building deteriorate at a faster or slower rate depending on materials and methods of construction, environmental conditions and the use of the building [19]. These families occupied these houses as a donation due to tsunami disaster in December 2004. They are not rich enough to maintain these houses as required. It is noted that some have taken to repair walls but it has failed. At the discussions with these users, the author realized that they are afraid to make changes on 
walls and attend modification or repairing walls as this technology is new to them.

\section{Results and Discussion}

Defects of earth buildings can assume two main forms: deficiencies of surface coatings; and, structural defects [7]. In this study it is found that most of the walls are protected by lime wash and in some walls decorated with coloured paint applied on lime wash. Therefore, CSRE walls require surface coating which should be based on soil or lime. After applying lime wash, colour painting can be applied on walls to keep a good appearance [3]. When observing the present condition of CSRE walls, cracks at CSEB wall junctions, peeling of plaster, water borne erosion and soil erosion at base of walls are the defects identified in this housing project. Same types of defects have been identified on CSRE walls in research conducted by Vasilios \& Walker [7]. This housing project was commenced as a result of finding cost effective walling methods in Sri Lanka in 2004 by CHPB. Author was a member of the team which developed CSRE technology from 2004. Since steel slip-form mould was used as support for casting CSRE walls, CSEB columns were cast at the junctions to get a good bonding between the wall and the corners. It was found that making corners need to be developed to avoid this separation cracks at wall junctions, hence pre cast CSRE wall junctions were introduced [20]. From the analysis based on defects of CSRE walls, it is found that $60 \%$ of houses are in good condition, $27 \%$ are in moderate condition and only $13 \%$ are in poor condition. When comparing the existing condition and the level of maintenance, good condition houses have been well maintained and moderate and poor condition houses have been poorly maintained during this 13 year of period. Maintaining a house, including cleaning, is necessary to fulfil its function and present a good appearance. It is highly desirable but hardly feasible to produce buildings that are maintenance free [19]. Soil erosion cases that have been noted at the base of gable side of external walls in most of the houses may be due to rain water gathered at the base of these walls. Water is a major agent of decay for earth buildings. Therefore, any routine maintenance work should primarily include measures to prevent deterioration from the effects of water [7].
It is highly recognized by the users that CSRE walls have good cooling effect in this housing project but most of the users did not make a good comment of the durability and the strength of the walls. This community needs a program on CSRE walling method and its maintenance to keep them aware on the acceptability of this technology. Since the author is continuingly carrying out development of CSRE walls in Sri Lanka, it is realized that cause of deterioration is not only due to the effect of water but also poor quality in construction in few of the houses at the later part of the this housing project. Though CSRE is one of the cost effective methods of wall construction it needs high supervision on quality control when constructing on site.

\section{Conclusion}

i. It is revealed that CSRE wall needs surface coating based on lime or earth to protect wall erosion and maintain good living conditions in the house. Colour paint can be applied to make the wall to be of good appearance.

ii. Wall cracks at CSEB wall junctions, peeling of plaster and soil erosion at base of walls are the defects identified in CSRE walls after a 13 year period. Majority of users (87\%) maintained CSRE walls are in a satisfactory condition while living there without fear during the last 13 years. Economical wall repairing method is to be introduced to these users with an awareness program on CSRE wall construction as they are the people now living in these houses.

iii. CSRE wall junctions can be included along with proper supervision for the construction of CSRE walls to avoid separation cracks at wall junctions in future constructions.

iv. It is identified by the users of this housing project that CSRE walls have good cooling effect and most of CSRE walls are still in good condition with low level maintenance.

v. Three sample houses constructed under proper supervision are in good condition without any defects for 13 year and the occupants are still satisfied about the construction. Therefore CSRE wall technology needs high supervision at construction stage to keep its durability, strength, and especially to be acceptable to the users. 


\section{Further study}

It is necessary to find suitable cost effective repairing methods of cracks for 13 year old CSRE walls and apply them in one house (No 15 or 16). An awareness program should be conducted for all users of this housing project regarding CSRE walling methods and demonstrate the repairing methods to enable them to attend to them when necessary.

\section{Acknowledgement}

Author acknowledges occupants of houses of the project who supported this study by providing history of CSRE houses for 13 years period and describing their views on CSRE walls.

\section{References}

1. Harris, C., Earth Building - Techniques, applications and potential, Centre for Alternative Technology, Clean Slate Magazine.

2. Golebiowski, J., Rammed earth architecture's journey to the high hills of the Santee and its role as an early concrete, Thesis for the Degree Master of Science Historic Preservation, 2009, pp 303 - 312.

3. Kandamby, G. W. T. C., "Use of Cement Stabilized Rammed Earth for Load Bearing Wall with Appropriate Finishes - Case Study", International Journal of Current Engineering and Technology, Vol 8, No.2, 2018, pp 303 - 312.

4. Jaquin, P. A., Augarde, C. E., \& Gerrard, C. M., "Analysis of Historic Rammed Earth Construction, Structural Analysis of Historical Constructions", 9 $9^{\text {th }}$ Young Geotechnical Engineers Conference, New Delhi, 2006.

5. Jayasinghe, C. \& Kamaladasa, N. "Structural Properties of Cement Stabilized Rammed Earth", ENGINEER Journal of the Institution of Engineers, Sri Lanka, Vol. xxxviii. no.03, 2005, pp.23-30.

6. Walker, P. Rammed earth: design and construction guidelines, BRE Book shop, Great Britain, 2005.

7. Vasilios, M. \& Walker P. A., Review of Rammed Earth Construction, Natural Building Technology Group, Department of Architecture \& Civil Engineering, University of Bath, United Kingdom, 2003.

8. Jayasinghe, C. \& Kamaladasa, N. “Compressive Strength Characteristics of Cement Stabilized Rammed Earth Walls" Science Direct, Construction and Building materials, 21,2007, pp. 1971-1976.
9. Arandara, K. P. \& Jayasinghe, C. “Identification of Durability Problem in Earth Building", ENGINEER Journal of the Institution of Engineers, Sri Lanka, Vol. xxxx. no.04, Sri Lanka, 2007, pp.14-21.

10. Windstorm, B., “A Report of Contemporary Rammed Earth Construction and Research in North America", International Symposium on Innovation \& Sustainability of Structures in Civil Engineering Xiamen University, China. 2011.

11. Jayasinghe, C., "Comparative Performances of Burnt Clay Bricks and Compressed Stabilized Earth Bricks and Blocks", ENGINEER Journal of the Institution of Engineers, Sri Lanka, Vol. xxxx. No.02, Sri Lanka, 2007, pp.33-40.

12. Kamaladasa N. \& Jayasinghe, C. "Development of Efficient Construction Technique for Rammed Earth", Annual Transactions of Institution of Engineers, Sri Lanka, 2005.

13. Kandamby, G. W. T. C. "Cement Stabilized Rammed Earth for Load Bearing Walls of Two Storey House - Case Study", Annual sessions of Institution of Engineers, Sri Lanka, Oct. 2015, pp 15 $-22$.

14. Kandamby, G. W. T. C. "Design and Construction Cement Stabilized Rammed Earth Walls for Single Storey Housing - Case Study", Annual Transactions of Institution of Engineers, Sri Lanka, 2014, pp 19 -26.

15. The British Standards Institution, British standard: Code of practice for the use of masonry Part 1: Structural use of unreinforced masonry, (BS 25628 part 1- 2005), London.

16. Delgado, M. C. J. \& Guerrero, I. C., "The Selection of Soils for Unstabilised Earth Building: A Normative Review", Construction and Building Materials, Spain, 21, 2005, pp.237251.

17. Andrew, P. DiGiamm, "Case Study: Ten years after", JLC online article, 2005.

18. Hadjri, K., Osmani, M., Baiche, B. and Chifunda, C. "Attitudes Towards Earth Building for Zambian Housing Provision", Proceedings of the Institution of Civil Engineers: Engineering Sustainability, 160 (3), 2007, pp.141- 149.

19. Seeley, I. H., Building Maintenance, 2nd Edition, PALGRAVE, New York, 1987.

20. Jayasinghe, C. \& Kandamby, G. W. T. C., "Cement Stabilized Rammed Earth Wall Junctions of Two Storey Houses", Proceedings of the Symposium on Civil Engineering Research for Industry, University of Moratuwa,2011, pp 119 123. 